\title{
Photoacoustic and nephelometric spectroscopy of aerosol optical properties with a supercontinuum light source
}

\author{
N. Sharma ${ }^{1}$, I. J. Arnold ${ }^{2}$, H. Moosmüller ${ }^{2}$, W. P. Arnott ${ }^{3}$, and C. Mazzoleni ${ }^{1}$ \\ ${ }^{1}$ Atmospheric Science Program and Physics Department Michigan Technological University, \\ 1400 Townsend Drive Houghton MI, 49931, USA \\ ${ }^{2}$ Division of Atmospheric Sciences, Desert Research Institute, 2215 Raggio Pkwy Reno, NV 89512, USA \\ ${ }^{3}$ Physics Department, University of Nevada, 1664 N Virginia St Reno, NV 89557, USA
}

Correspondence to: N. Sharma (noopurs@mtu.edu) and C. Mazzoleni (cmazzoleni@mtu.edu)

Received: 20 June 2013 - Published in Atmos. Meas. Tech. Discuss.: 11 July 2013

Revised: 17 October 2013 - Accepted: 30 October 2013 - Published: 10 December 2013

\begin{abstract}
A novel multi-wavelength photoacousticnephelometer spectrometer (SC-PNS) has been developed for the optical characterization of atmospheric aerosol particles. This instrument integrates a white light supercontinuum laser with photoacoustic and nephelometric spectroscopy to measure aerosol absorption and scattering coefficients at five wavelength bands (centered at 417, 475, 542, 607, and $675 \mathrm{~nm}$ ). These wavelength bands are selected from the continuous spectrum of the laser (ranging from 400-2200 nm) using a set of optical interference filters. Absorption and scattering measurements on laboratory-generated aerosol samples were performed sequentially at each wavelength band.

To test the instrument we measured the wavelength dependence of absorption and scattering coefficients of kerosene soot and common salt aerosols. Results were favorably compared to those obtained with a commercial 3-wavelength photoacoustic and nephelometer instrument demonstrating the utility of the SC light source for studies of aerosol optical properties at selected wavelengths. Here, we discuss instrument design, development, calibration, performance and experimental results.
\end{abstract}

\section{Introduction}

Atmospheric aerosols are major players in determining the Earth's radiation budget (Horvath, 1993). Different particles have different absorption and scattering spectra. For example, soot particles absorb solar radiation over a broad wavelength range from the ultraviolet to the infrared; in contrast, some organic particles absorb weakly in the visible, while brown carbon particles absorbs mostly in the UV-blue part of the solar spectrum (Chen and Bond, 2010). Mineral dust particles also exhibit characteristic scattering and absorption spectra depending on their composition (e.g., amount of iron oxides; Moosmüller et al., 2012), size, and morphology. The absorption of solar radiation by these particles contributes to the heating of the surrounding atmosphere, while cooling the Earth's surface, thereby affecting convective processes and cloud properties and lifecycle. Some particles including most organics, sulphates, and salts, scatter solar radiation efficiently without absorption, hence cooling the atmosphere (Chýlek et al., 1995) and reducing atmospheric visibility (Tang et al., 1981; Moosmüller et al., 2009a). These different aerosol species are released or formed into the atmosphere as a result of anthropogenic, biogenic, and other natural processes (like wind-driven dust entrainment) and significantly affect climate by means of their direct and indirect radiative forcing (Solomon et al., 2007).

The efficiency of aerosols to absorb and scatter solar radiation depends upon particle characteristics like size, morphology, and refractive index. Therefore, aerosol absorption and scattering coefficients exhibit distinct wavelength dependencies. A number of experimental studies have been conducted to investigate the wavelength dependence of scattering and absorption of atmospheric aerosol exhibiting complex mixing of different components (e.g., Gyawali et al., 2012, 2013; Flowers et al., 2010; Bergstrom et al., 2007). Several controlled laboratory studies have also been performed, 
generating aerosols including soot, salt, and biomass burning particles and controlling or studying in detail the mixing state of different components (e.g., Sheridan et al., 2005; Lewis et al., 2008; Cross et al., 2010). Absorbing carbonaceous aerosols are termed light absorbing carbon and include soot and brown carbon (Bond and Bergstrom, 2006; Andreae and Gelencsér, 2006). An inverse dependence of the absorption coefficient on wavelength $\lambda$ (i.e., $\lambda^{-1}$ ) has typically been observed for small soot particles (e.g., Bergstrom et al., 2002). In general, over a limited wavelength range, the absorption coefficient is approximately proportional to $\lambda^{-b}$. While for small soot particle $b \sim 1$, for brown carbon particles that can be generated for example from smoldering biomass burning, the value of the exponent $b$ is wavelength-dependent and is typically significantly greater than 1 for shorter visible and UV wavelengths leading to much enhanced absorption in the blue part of the solar spectrum (e.g., Sun et al., 2007; Lewis et al., 2008; Lack et al., 2012; Ramanathan et al., 2005). Salts, such as $\mathrm{NaCl}$ and $\left(\mathrm{NH}_{4}\right)_{2} \mathrm{SO}_{4}$, are non-absorbing in the visible and contribute to light extinction mostly by scattering the incident radiation (Abu-Rahmah et al., 2006; Irshad et al., 2009; Chamaillard et al., 2003; Schnaiter et al., 2006).

Measurement of the wavelength dependence of aerosol optical properties is a challenging task, due to the dependence of optical properties on highly variable parameters such as mixing, morphology, composition, and size, and due to the inhomogeneous distribution of aerosols in the atmosphere. Integrating nephelometry is the most common technique for measuring in-situ aerosol scattering coefficients (Heintzenberg and Charlson, 1996; Abu-Rahmah et al., 2006). The two most common types of nephelometers are: (a) direct integrating nephelometer and (b) reciprocal integrating nephelometer (Marcos, 1999). A number of in-situ measurement techniques for the quantification of light absorption by aerosols have been available for years. The photoacoustic technique is currently gaining recognition due to its higher accuracy with respect to filter-based instruments and due to the recent availability of commercial instruments (Moosmüller et al., 2009b; Lack et al., 2008). Several photoacoustic instrument designs have been developed by different groups for applications in the field of atmospheric aerosol. Modern photoacoustic instruments typically exploit the high brightness and directionality of laser sources; however, these sources are generally quasi-monochromatic.

The commercially available aerosol photoacoustic spectrometer (PASS-3, by DMT Inc.), has evolved from its prototype single wavelength photoacoustic spectrometer (Arnott et al., 1999) and the dual wavelength photoacoustic spectrometer (Lewis et al., 2008) to the 3-wavelength instrument typically operating at $405 \mathrm{~nm}, 532 \mathrm{~nm}$ and $781 \mathrm{~nm}$, each wavelength being generated by an individual laser. These instruments also simultaneously measure aerosol scattering by reciprocal nephelometric technique. From the simultaneous measurement of extensive absorption and scattering coefficients, one can obtain the aerosol single scattering albedo
(SSA), which is the ratio of the scattering to the extinction coefficients. The SSA is an intensive quantity and is one of the fundamental parameters needed to calculate the aerosol radiative forcing (e.g., Chylek and Wong, 1995). The simultaneous measurement of absorption and scattering coefficients with these instruments allows obtaining additional information from the same aerosol sample, in contrast to instruments which provide only an estimate of absorption, such as the aethalometer, the Particle Soot/Absorption Photometer (PSAP), and the Multi-Angle Absorption Photometer (MAAP)).

A photoacoustic instrument discussed in Lack et al. (2006) uses a multi-pass cell to increase sensitivity at a single wavelength $(532 \mathrm{~nm})$. The latest multi-wavelength development of this instrument operates at three wavelengths: 404, 532, and $658 \mathrm{~nm}$. Another multi-wavelength photoacoustic instrument developed by Ajtai et al. (2010) at the University of Szeged, Hungary measures the aerosol absorption simultaneously at four different wavelengths $(266,355,532$, and $1064 \mathrm{~nm})$ by using a single laser source and higher harmonics generation. In a recent development, a tunable narrow linewidth Optical Parametrical Oscillator (OPO) has been combined with a photoacoustic cell for the sequential measurement of aerosol absorption coefficients over a wide spectral range (Haisch et al., 2012).

The main motivation behind the development of new instrumentation with increasing number of operating wavelengths is the role that wavelength dependencies of aerosol absorption and scattering have on radiative forcing and climate. The use of a broadband laser source is an alternative to tunable lasers (such as the OPO) or the increased number of single wavelength sources in current photoacoustic spectrometers (as in the PASS-3). Supercontinuum, white light lasers are currently gaining great interest in biomedical applications, optical communications, as well as in fundamental spectroscopy due to their broad spectral bandwidth, high power, high stability, and relatively flat spectrum. Although supercontinuum generation has its roots in the pioneering work by Alfano and Shapiro in the early 1970s (Alfano and Shapiro, 1970), compact and robust supercontinuum lasers have become commercially available only in the last decade. Typically in these table-top systems, the supercontinuum generation is based on the spectral broadening of ultrashort laser pulses in photonic crystal fibers due to their high optical nonlinearity (Russell, 2003; Knight, 2003; Ranka et al., 2000; Dudley et al., 2006).

We present here the development of a new instrument that combines a supercontinuum light source with a photoacoustic-nephelometer spectrometer (SC-PNS) for the simultaneous measurement of the scattering and absorption coefficients of an aerosol sample at a given wavelength band. First, we describe the prototype development and its calibration, and then we discuss some preliminary tests performed with different laborator-generated aerosols; followed by a discussion on the performance of the instrument. The broad 


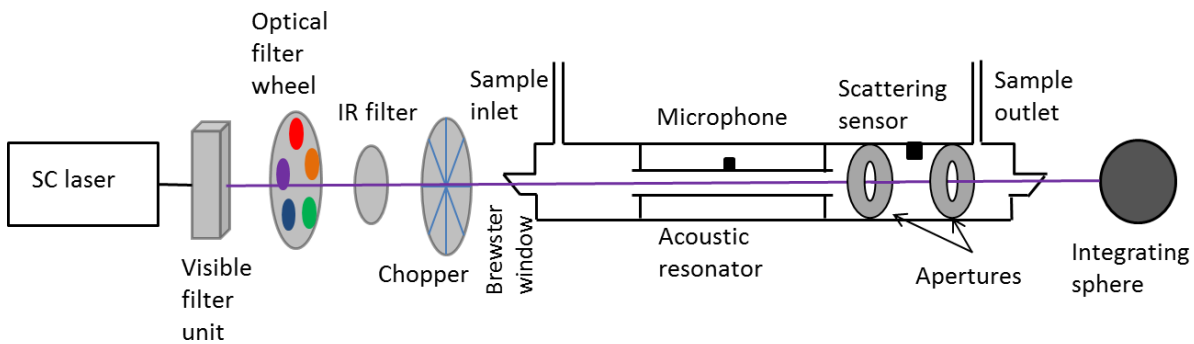

Fig. 1. Schematics of the supercontinuum integrated photoacoustic-nephelometer spectrometer.

spectrum of the supercontinuum source that covers almost the entire tropospheric solar spectrum, currently enables us to characterize the aerosols at five wavelength bands in the visible, and future work should expand this capability to the near-infrared (NIR).

\section{Instrument description}

In Fig. 1, we show the schematic of the multi-wavelength photoacoustic-nephelometer spectrometer discussed here. The instrument uses a supercontinuum laser as a broadband light source combined with photoacoustic and nephelometery cells that allow measuring scattering and absorption of aerosol particles over a broad wavelength range.

The supercontinuum Laser SC400 (Fianium Inc.) used in our study has a core pumped $\mathrm{Yb}$-doped fiber as a master oscillator and uses a passive mode locking technique that enables the emission of short laser pulses $(<10 \mathrm{ps})$ with a high pulse repetition rate $(20 \mathrm{MHz})$. The radiation from the master oscillator is amplified using a polarization-maintaining double-clad $\mathrm{Yb}$-doped fiber, pumped by a high power laser diode. The high peak power pulses emitted by the amplifier enter then a highly nonlinear photonic crystal fiber that causes large spectral broadening resulting in supercontinuum emission starting at a wavelength of $\sim 400 \mathrm{~nm}$, peaking around $1200-1300 \mathrm{~nm}$, and extending beyond $2200 \mathrm{~nm}$. A detailed discussion of the process of supercontinuum generation in nonlinear $\mathrm{Yb}$-doped double-clad fibers can be found in Roy et al. (2007). The beam exiting the fiber is collimated with a lens-based collimator. The spectrum of the collimated laser beam has been obtained with a Fieldspec 3 Portable Spectroradiometer (ASD Inc.) and is shown in Fig. 2.

In the SC-PNS, the collimated beam from the supercontinuum laser is passed through a combination of optical filters used to select the wavelength bands of interest. First, the visible part of the supercontinuum spectrum is selected by using a visible light bandpass filter unit. This filter unit consists of two dichroic mirrors which reflect the visible wavelengths up to $\sim 800 \mathrm{~nm}$ that exits the filter unit as a visible white light beam. The NIR wavelengths are transmitted through the dichroic mirrors and are dissipated. Figure 2 also shows the spectrum of the beam filtered by the visible light filter with

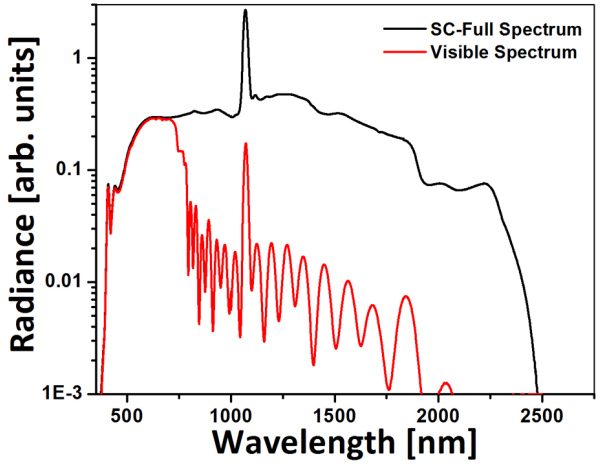

Fig. 2. Supercontinuum full spectrum and spectrum with visible filter unit.

a logarithmic radiance axis. Notice the peak at $1070 \mathrm{~nm}$ corresponding to the residual of the fundamental emission from the master source.

The selection of different wavelength bands is achieved by using a series of single-bandpass filters (BrightLine filters by Semrock) mounted on a filterwheel (Edmund Optics) which can be rotated manually by the operator. During the instrument calibration, the total measurement time on each filter was five to six minutes, while during the experiments, it was three to four minutes, after which the filter wheel was rotated to select a different wavelength band. Aerosols do not exhibit sharp spectral features; therefore, the bandpass width of each filter was chosen as a tradeoff between the need for modest spectral resolution and significant laser power (the photoacoustic signal is directly proportional to the laser power, see Eq. 1). The filter center wavelengths were chosen to cover most of the visible spectrum available from the supercontinuum source. The optical specifications each band pass filter are listed in Table 1.

The spectrum of the beam emerging from the visible filter unit shown in Fig. 2 contains some residual NIR light beyond $800 \mathrm{~nm}$. An IR blocking filter (FGS900 Thorlabs) was used in front of the filter wheel to greatly reduce the power of this spurious NIR component. Figure 3 represents the spectra obtained with the visible filter unit, the IR blocking filter, and each one of the interference filters. 
Table 1. Optical specifications of each bandpass filters used in the supercontinuum integrated photoacoustic-nephelometer spectrometer.

\begin{tabular}{lrrrrr}
\hline $\begin{array}{l}\text { Filter } \\
\text { Identifier }\end{array}$ & $\begin{array}{r}\text { Center } \\
\text { Wavelength [nm] }\end{array}$ & $\begin{array}{r}\text { Transmission } \\
\text { Band [nm] }\end{array}$ & $\begin{array}{r}\text { Bandwidth } \\
{[\mathrm{nm}]}\end{array}$ & $\begin{array}{r}\text { Average } \\
\text { Transmittance [\%] }\end{array}$ & $\begin{array}{r}\text { Resulting Laser } \\
\text { Power [mW] }\end{array}$ \\
\hline F1 & 417 & $387-447$ & 64.2 & $>90$ & 15.6 \\
F2 & 475 & $450-500$ & 56.4 & $>90$ & 26.5 \\
F3 & 542 & $517-567$ & 56.8 & $>93$ & 45.6 \\
F4 & 607 & $572-642$ & 80 & $>92$ & 86.4 \\
F5 & 675 & $641.5-708.5$ & 73.7 & $>90$ & 64.4 \\
\hline
\end{tabular}

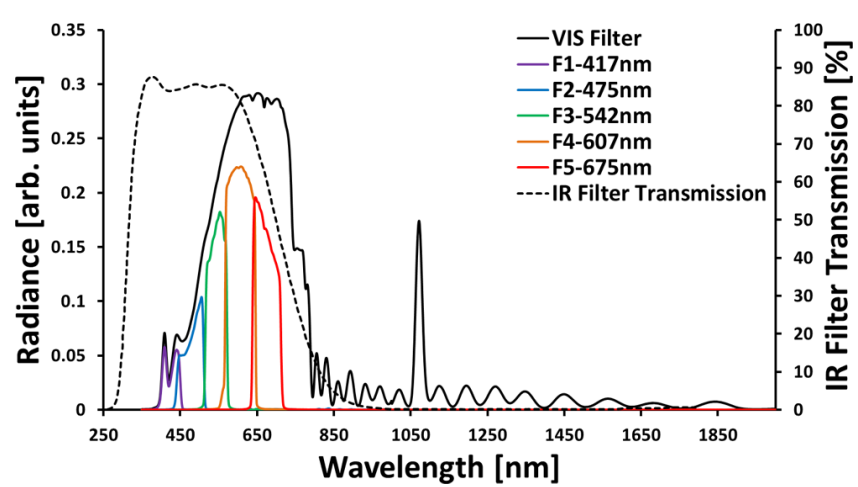

Fig. 3. Radiance spectra from single band filters (colored lines). Longer wavelengths are filtered out by using an infrared blocking filter (dashed line represents the transmission spectrum of the IR filter on the right vertical axis).

The aerosol measurement unit used in our experiments consists of two cylindrical cells connected in series. The first cell is used for the measurement of absorption coefficients (photoacoustic spectrometer) and the second for the measurement of scattering coefficients (reciprocal nephelometer) (Fig. 1). Particles flow through both cells along their axis, and the laser beam propagates coaxial to the airflow. The sample flow is maintained at a rate of $\sim 0.6 \mathrm{Lpm}$ by using a critical orifice and a pump. The critical orifice also acoustically isolates the photoacoustic cell from the pump.

The photoacoustic cell consists of an acoustic resonator of length $\sim 118 \mathrm{~mm}$ which is approximately equal to half of the acoustic wavelength, and diameter $6.35 \mathrm{~mm}$. The resonator is equipped with a hearing aid microphone (Knowles Inc. model\# EK 23028) to measure the acoustic signal generated in the photoacoustic process (Tam, 1986). The optical power at the filter-selected wavelength band is modulated at the resonant acoustic frequency of the cell $(\sim 1.5 \mathrm{kHz})$ by using an optical chopper (New Focus model \#3501). The modulated light enters the cell through a Brewster window. When sample particles absorb the modulated laser radiation, an acoustic signal is generated. The resonator amplifies the signal improving the signal to noise ratio. The microphone mounted in the resonator at the acoustic antinode detects the acoustic signal as a pressure change on its surface. The absorption coefficient of the aerosol is given by:
$\beta_{\mathrm{abs}}=\frac{P_{\mathrm{m}}}{P_{\mathrm{L}}} \frac{A_{\text {res }} \pi^{2} f_{0}}{(\gamma-1) Q}$,

where, $P_{\mathrm{m}}$ is the pressure at the microphone at the resonant frequency $f_{0}, P_{\mathrm{L}}$ is the laser power; $A_{\text {res }}$ is the geometric cross section of the resonator, $\gamma$ is the ratio of specific heat at constant pressure and volume, and $Q$ is the quality factor of the resonator (Rosencwaig, 1980; Arnott et al., 1999; Lewis et al., 2008; Moosmüller et al., 2009b) 20.9 for our cell.

The scattering cell incorporates a reciprocal integrating nephelometer design (Marcos, 1999). The cell is equipped with two apertures of $\sim 6.5 \mathrm{~mm}$ diameter, and the scattering measurements are performed in the volume between these apertures. The apertures serve to decrease background radiation and to limit the truncation angle to $\pm 5 \mathrm{deg}$. The "scattering photodiode" (ThorLabs FDS100) used to detect the scattering signal is mounted on top of the nephelometer cell between the two apertures. A Lambertian diffuser is placed in front of the photodiode to provide an integrated cosineweighted scattering signal. The laser radiation that propagates through the photoacoustic/nephelometer cells without being absorbed or scattered by the aerosols and gases within the cells, is detected by a photodiode (ThorLabs FDS100, we will refer to it as the "extinction photodiode"), mounted on an integrating sphere for measuring the transmitted optical power.

A control box incorporates an HEPA filter and a solenoid switch that the operator (or a computer digital signal) can periodically turn $\mathrm{ON}$ to let the sample flow through the HEPA filter before reaching the measurement cell; this procedure is used to measure the background signal with particles removed from the sample. The control box also contains a sensor to measure the sample air pressure. The scattering and absorption background signals are due to electronic noise, molecular Rayleigh scattering, absorption by gases like $\mathrm{NO}_{2}$ present in the sampled air, and scattering or absorption of the laser beam at the windows and walls of the cells. In our experiments, background measurements were done before and after every minute of sample measurement. Table 2 shows the statistics (average, standard deviation and count) for the background signals for absorption and scattering as measured at each wavelength band. All data used in the statistics, correspond to an individual measurement time of about 
$2-3 \mathrm{~s}$. The background values of absorption and scattering are subtracted from the measured values to obtain the actual absorption and scattering by the aerosol particles alone. An integrated capacitive and band-gap sensor (Sensirion model\# SHT75) was used to measure relative humidity and temperature of the aerosol sample. Since the sensor is sensitive to particle contaminations, it was installed after a particle filter at the outlet of the instrument.

Instrument data are acquired with a National Instruments data acquisition card that has 8 synchronous channels (NI PCI-6143) and a desktop PC. The card also provides a TTL signal to drive the chopper at the reference frequency and phase. LabView software includes functions of lock-in amplifier and Fast Fourier Transform (FFT) analyzer for phase sensitive detection of the photoacoustic signal and reduction of the noise in the microphone signal (Arnott et al., 1999; Scofield, 1994; Scott et al., 2001). The FFT is also used to measure the laser transmitted and scattered power.

During some of the experiments we simultaneously operated a commercial 3-wavelength photoacoustic/nephelometer spectrometer (PASS-3 by DMT Inc.) and a Scanning Mobility Particle Sizer (SMPS by TSI model\# 3080). The PASS-3 simultaneously measures the aerosol scattering and absorption coefficients at 405, 532 and $781 \mathrm{~nm}$, while our current instrument measures scattering and absorption at one wavelength at a time.

\section{Aerosol generation and delivery system}

Laboratory generated kerosene soot and nebulized salt $(\mathrm{NaCl})$ aerosols were used to calibrate and test the instrument. Soot was generated with a simple kerosene lamp sold for domestic use. Salt in aqueous solution was nebulized using an ultrasonic mist maker or an aerosol generator (TSI 3076). The nebulized salt solution was then dried by passing it through a dessicator (anhydrous drierite) that reduced the sample RH value to $\sim 30 \%$ before delivery to the instrument. The aerosol sample was forced through the sample line by an eductor pump which provided diluted, relatively steady aerosol concentrations.

Because our instrument operated only at one wavelengthband at a time, in order to compare the aerosol optical properties obtained at each wavelength-band, the aerosol concentration needed to vary slowly and monotonically and the size distribution needed to change as little as possible. This was achieved by using an iron lung, which is basically a steel cylindrical drum having a diameter of $64 \mathrm{~cm}$ and height of $86 \mathrm{~cm}$. It is lined with a conductive liner and has a capacity of $277 \mathrm{~L}$ which takes $15-20 \mathrm{~min}$ to be fully filled with kerosene soot (diluted with air) with a flow rate of $\sim 20 \mathrm{Lpm}$ (Arnold et al., 2013). As the aerosol is drawn from the lung by the instruments, the bag gradually collapses resulting in a slow and monotonically decaying particle concentration with small variations in the size distribution. The sampling
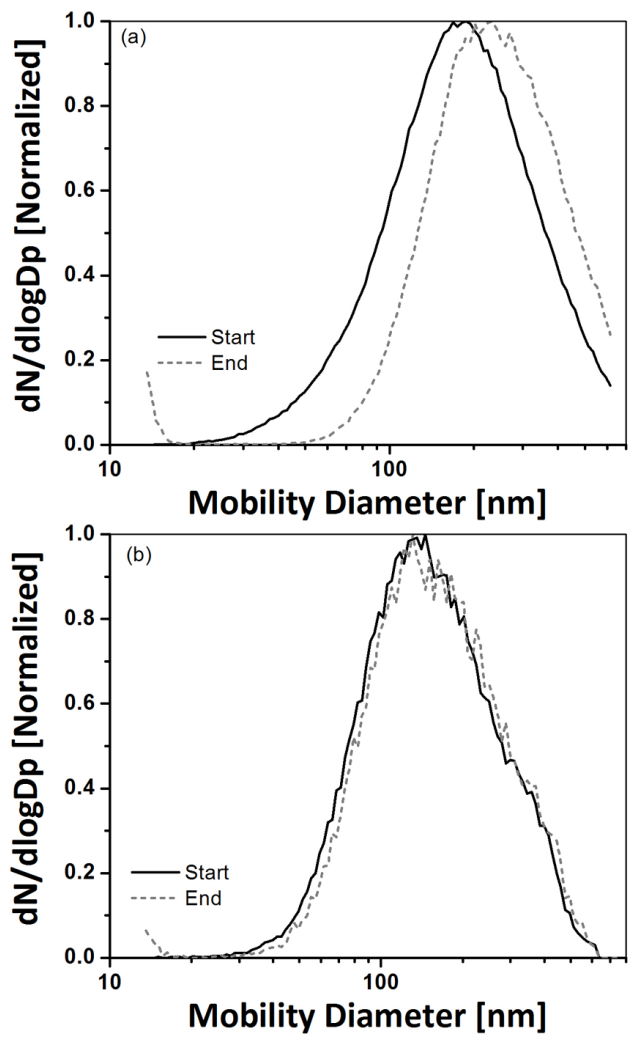

Fig. 4. Normalized size distribution of (a) soot and (b) salt aerosols measured by an SMPS during the experiment. The black curve indicates the initial size distribution at the beginning of the experiment and the grey dashed curve indicates the size distribution toward the end of experiment.

time from the lung was about $2 \mathrm{~h}$ as the flow used by the instruments added up to a total of about $2 \mathrm{Lpm}$. The typical absorption and scattering coefficients measured by the SCPNS and PASS- 3 at the iron lung output were in the order of $2000-3000 \mathrm{Mm}^{-1}$. The SMPS was used for monitoring the size distribution and concentration of the aerosol sample delivered from the iron lung. The average mode number diameter (MND) and geometric standard deviation (GSD) for soot were $208( \pm 16) \mathrm{nm}$ and $1.77( \pm 0.03) \mathrm{nm}$, respectively over a period of $2 \mathrm{~h}$ and $6 \mathrm{~min}$. For salt, the average MND and the GSD measured by SMPS were $140( \pm 7) \mathrm{nm}$ and $1.77( \pm 0.012) \mathrm{nm}$, respectively over a period of $2 \mathrm{~h}$ and $6 \mathrm{~min}$. The number in parenthesis represents one standard deviation (Fig. 4).

\section{Instrument calibration}

The calibration procedure of the SC-PNS involves four steps: (1) calibration of the extinction photodiode, (2) measurement of the resonance response of the acoustic cell, (3) calibration of the scattering photodiode (including the diffuser angular response), and (4) absorption calibration (calibration of the microphone response). 
Table 2. Statistics (average, standard deviation and count) for absorption and scattering background measurements.

\begin{tabular}{|c|c|c|c|c|c|}
\hline \multirow{2}{*}{$\begin{array}{l}\text { Filter center } \\
\text { wavelength }[\mathrm{nm}]\end{array}$} & \multicolumn{2}{|c|}{ Absorption } & \multicolumn{2}{|c|}{ Scattering } & \multirow{2}{*}{$\begin{array}{l}\text { Number of } \\
\text { measurements }\end{array}$} \\
\hline & Average & St. Dev. & Average & St. Dev. & \\
\hline 417 & 39 & 12.4 & 2264 & 345 & 1106 \\
\hline 475 & 6 & 8.0 & 2254 & 7.3 & 1061 \\
\hline 542 & 35 & 4.4 & 2134 & 6.4 & 1035 \\
\hline 607 & 80 & 3.0 & 1833 & 8.2 & 1068 \\
\hline 675 & 65 & 3.2 & 1958 & 197 & 1101 \\
\hline
\end{tabular}

The extinction photodiode is calibrated by comparing the output signal of the photodiode with the power of the laser at the different wavelength bands as measured by a calibrated power meter (ThorLabs, PM100D) at the end of SC-PNS cells.

The resonance response of the acoustic cell is measured using a piezoelectric transducer by scanning its emission frequency and recording the signal at the microphone. The microphone signal is then compared to a Lorentzian resonance curve and a least square fit is performed using a second order polynomial to obtain the values of the resonator quality factor, $Q$ and the resonance frequency, $f_{0}$ (Arnott et al., 1999).

The absorption and scattering calibration procedure for the SC-PNS is based on the measurement of single-pass light extinction. High sample concentrations yielding absorption or scattering coefficients up to $40000-60000 \mathrm{Mm}^{-1}$ are necessary to obtain a significant extinction signal (significantly higher than the extinction detection limit as reported in Table 3 ) in the order of $1-3 \%$ (Eq. 3) due to the short optical path $L$ within the cells $(405 \mathrm{~mm})$. The scattering calibrations at the different wavelengths, are carried out using non-absorbing aerosols (e.g., salt) while absorbing aerosols (e.g., soot) are used for absorption calibrations. The calibration coefficients are determined by comparing the scattering and absorption signals to the extinction signal and exploiting the optical closure relation given by:

$\beta_{\mathrm{ext}}=\beta_{\mathrm{sca}}+\beta_{\mathrm{abs}}$,

where $\beta_{\text {ext }}$ is the extinction coefficient calculated from the equation:

$P_{\mathrm{PD}}=P_{\mathrm{L}} \exp \left(-\beta_{\mathrm{ext}} L\right)$,

and $\beta_{\mathrm{abs}}$ is the absorption coefficient, $\beta_{\mathrm{sca}}$ is the scattering coefficient, $P_{\mathrm{L}}$ is the laser power in absence of aerosols, $L$ is the length of the cell, and $P_{\mathrm{PD}}$ is the transmitted laser power detected by the extinction photodiode. Abu-Rahmah et al. (2006) describe the scattering calibration technique for the nephelometer using white (non-absorbing) aerosols. Ammonium sulphate $\left(\mathrm{NH}_{4}\right)_{2} \mathrm{SO}_{4}$ and Sodium Chloride $(\mathrm{NaCl})$ can be considered non-absorbing in the spectral range of interest. In our experiments we used $\mathrm{NaCl}$ dissolved in water and aerosolized with the system described earlier.
For non-absorbing aerosols $\beta_{\mathrm{abs}}=0$ and $\beta_{\mathrm{ext}}=\beta_{\mathrm{sca}}$, then $\beta_{\text {ext }}$ obtained from Eq. (3) is used to obtain the scattering calibration factor. With this aim, the signal measured by the scattering photodiode is plotted against the extinction signal; the slope of a linear fit gives the scattering calibration constant.

Similarly, the calibration constant for absorption is calculated using a strongly absorbing aerosol and Eqs. (2) and (3) with the calibrated scattering, and again using the extinction measurement. We used kerosene soot as a strongly absorbing aerosol (Arnott et al., 2000). The calibration constant for absorption is given by the slope of a linear regression of the microphone signal vs. the extinction minus the scattering signals.

Figure 5a shows the extinction vs. scattering plot for the scattering calibration check at all filter wavelengths during one of our experiments, and Fig. 5b shows the absorption vs. extinction-scattering plot for the absorption calibration check. Scattering and absorption calibration constants of $0.99( \pm 0.02)$ and $1.14( \pm 0.03)$, respectively were obtained in this instance within a confidence interval of $95 \%$.The variability in the calibration is calculated as the standard deviation of the calibration constants, as obtained from the absorption and the scattering calibrations at the five different filter wavelength bands. The variation within different calibrations is less than $15 \%$ for scattering and less than $8 \%$ for absorption. The graphs also show that there is no systematic wavelength-dependence in the calibration variability and that the instrument response is quite linear over large scattering and absorption ranges.

\section{Results and discussion}

After calibration, the SC-PNS was tested with kerosene soot and nebulized $\mathrm{NaCl}$ salt in two separate experiments and the results were compared to the PASS-3 data. As mentioned earlier, the PASS-3 operated continuously during the experiment measuring at three wavelengths simultaneously, while the SC-PAS was operated in sequence, one wavelength at a time; measurements were done with each optical filter for $\sim 1 \mathrm{~min}$. In the following discussion, we will refer to "run" as 

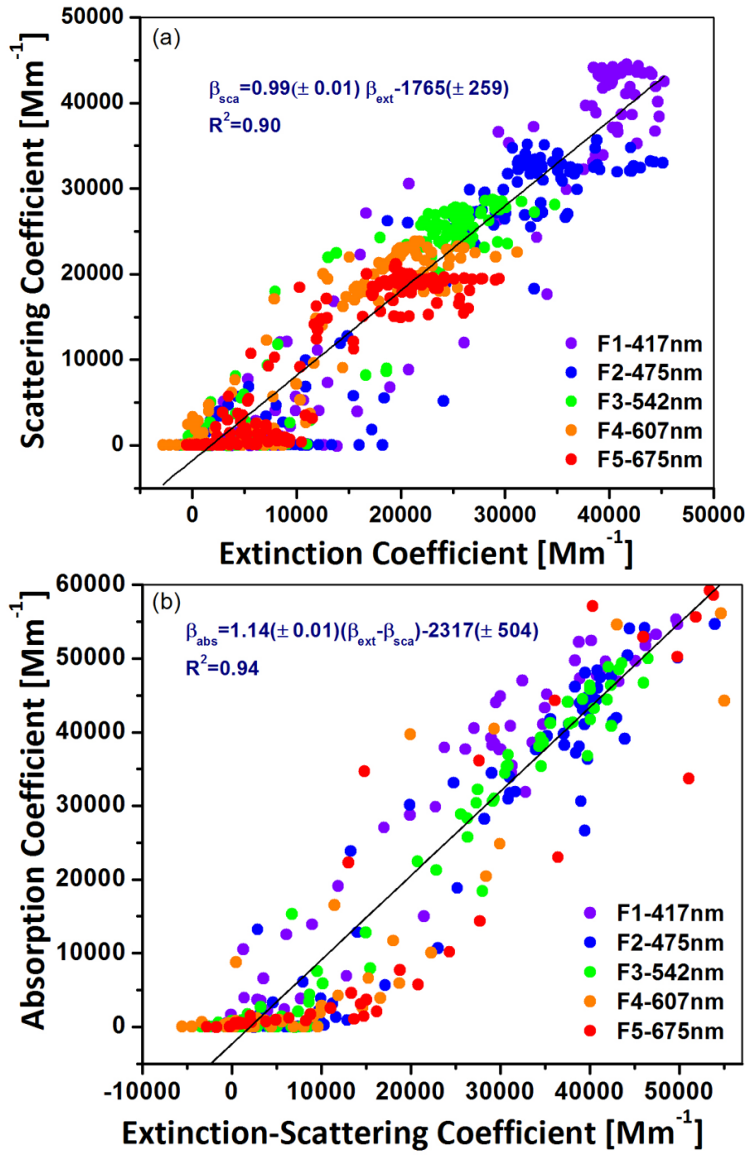

Fig. 5. (a) Scattering and (b) absorption calibration plots for the SC-PNS instrument at all five filter wavelengths. Colors correspond to the center wavelength of each filter.

a full set of the different optical filters (from 1 to 5). We performed background measurements before and after sample measurement on each filter. The experiment for each aerosol type lasted for about $2 \mathrm{~h}$ with 5-6 complete runs. The aerosol was sampled at a rate of $2 \mathrm{Lpm}$ from the iron lung, which has a capacity $277 \mathrm{~L}$ so the lung is expected to be able to deliver aerosols for $\sim 2 \mathrm{~h} 20 \mathrm{~min}$. The total time taken by 6 runs in an experiment was approximately $2 \mathrm{~h} 6 \mathrm{~min}$; therefore after 6 runs we started noticing a rapid drop in the aerosol concentrations by a third of the original value and we stopped measuring after that. A comparison of the data obtained from the two instruments is discussed next.

The PASS-3 and the SC-PNS data were first normalized to the average of the PASS-3 signal over the time correspondent to each wavelength of the first run. This was done to normalize for the changes in aerosol concentration over the span of the entire experiment and to allow for a direct comparison of the different SC-PNS wavelengths.

The two instruments operate at different wavelengths and different bandwidths; therefore, in order to compare the measurements, the absorption and scattering coefficients measured by the PASS-3 were interpolated over the spectrum of the supercontinuum through each filter. The interpolation for the wavelengths correspondent to the filters F1 and F2 was done using the Ångström exponent for absorption and scattering calculated from the 405 and $532 \mathrm{~nm}$ wavelengths from the PASS-3 using Eq. (4). The interpolation for the wavelengths correspondent to the filters F3, F4 and F5 was done using the Ångström exponents calculated from the $532 \mathrm{~nm}$ and $781 \mathrm{~nm}$ data from the PASS-3.

$\beta_{\mathrm{abs}(\mathrm{sca})}(\lambda)=C \cdot \lambda^{-\alpha_{\mathrm{abs}(\mathrm{sca})},}$

where, $C$ is a wavelength-independent constant and $\alpha_{\text {abs(sca) }}$ is the Ångström exponent for absorption or scattering (Moosmüller et al., 2011). The interpolated value at each wavelength was averaged over the wavelength bandwidth for each filter weighted by the spectral radiance transmitted by each filter (the radiance data from Fig. 3 were used) using Eq. (5).

$$
\begin{aligned}
& \left\langle\beta_{\mathrm{abs}(\mathrm{sca})}\right\rangle= \\
& \frac{\int_{\min }^{\lambda_{\max }}\left(\frac{\lambda}{\lambda_{\text {PASS }-3}}\right)^{\alpha_{\text {abs }(\text { sca })}} \beta_{\text {abs }(\text { sca })}(\lambda \text { PASS }-3) E(\lambda) d(\lambda)}{\int_{\lambda_{\min }}^{\lambda_{\max }} E(\lambda) d \lambda},
\end{aligned}
$$

where $\lambda$ is the wavelength between minimum $\left(\lambda_{\min }\right)$ and maximum $\left(\lambda_{\max }\right)$ of a single band filter and $E(\lambda)$ is the radiance transmitted by the filter at wavelength $\lambda$; $\beta_{\text {abs(sca) }}\left(\lambda_{\text {PASS- }}\right)$ is the absorption or scattering coefficient measured at wavelength ( $\left.\lambda_{\text {PASS-3 }}\right)$ by the PASS- $3 ; \alpha_{\text {abs(sca) }}$ is the Ångström exponent for absorption or scattering obtained from PASS-3 measurements for the respective wavelength pair.

A correction for background drifts of the PASS-3 was applied by linearly interpolating the background values between two consecutive background measurements. This procedure was not necessary for the SC-PAS due to the frequent zeroing and the high stability of the laser. The data so obtained from the PASS-3 were compared to the values of absorption and scattering measured by the SC-PNS. The wavelength dependencies of absorption and scattering for kerosene soot and $\mathrm{NaCl}$ measured by the SC-PNS and the PASS-3 are compared and discussed in the next section. The SC-PNS data presented in the following figures are the average of all the measurements at each wavelength band over the different runs. The error bars represent the square root of the sum of the squares of the standard errors (standard deviation divided by the square root of the number of data) of the measurements for each run, background error, and the estimated variability in the calibration (8\% in absorption and $15 \%$ in scattering). The error in the background is calculated as the standard error of the mean of the absorption and scattering signals obtained during background measurements (zeroing). 

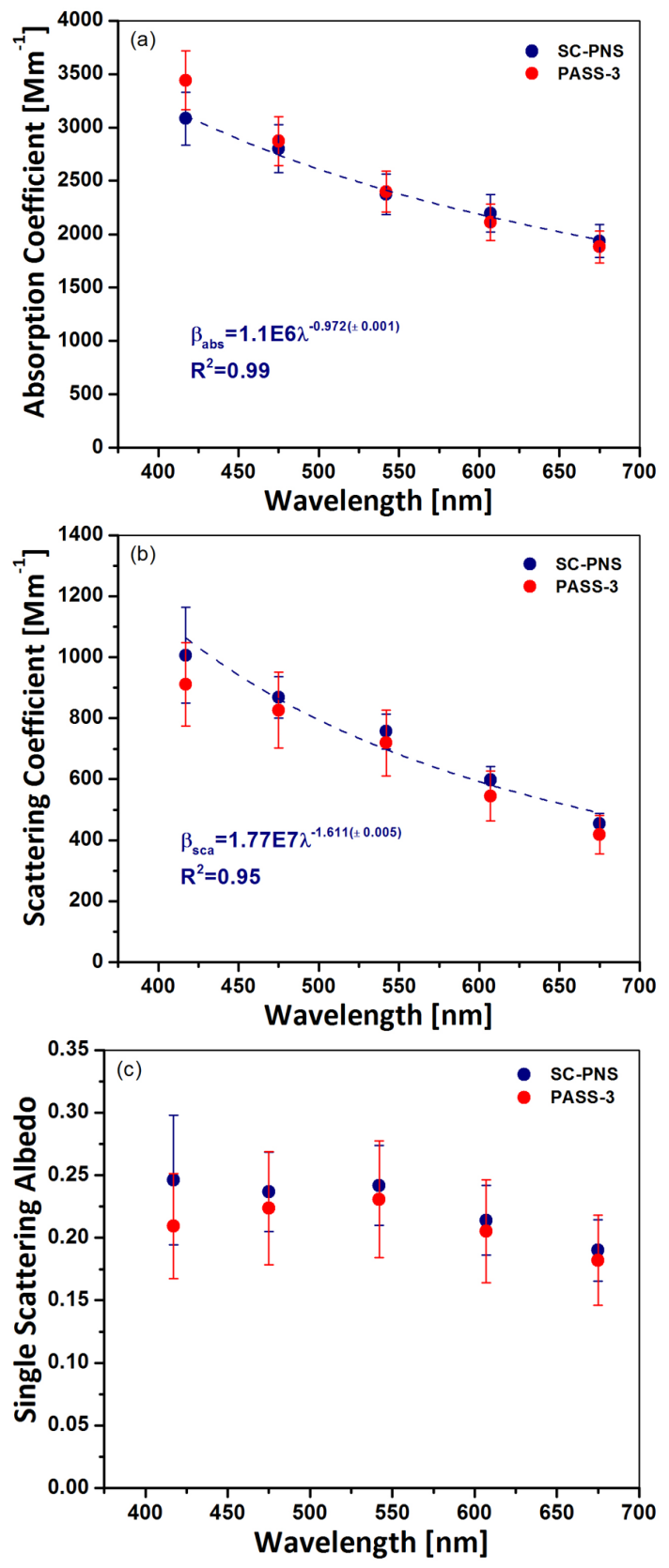

Fig. 6. (a) Absorption ( $\left.\beta_{\text {abs }}\right)$ and (b) scattering ( $\left.\beta_{\text {sca }}\right)$ coefficients of kerosene soot vs. wavelength $(\lambda)$ measured by PASS-3 and SCPNS, error bars indicate square root of the sum of squares of background error, standard deviation of mean (standard error) and calibration variability. (c) Wavelength dependence of single scattering albedo (SSA) of kerosene soot, error bars indicate the error propagated from absorption and scattering.

\subsection{Kerosene soot}

Figure 6a shows the absorption coefficient of soot as a function of wavelength with a power law fit of the SC-PNS data yielding an Absorption Ångström Exponent (AAE) of $\sim 0.972( \pm 0.001)$. This value is consistent with the $\lambda^{-1}$ dependence demonstrated in a number of theoretical and experimental studies previously conducted on kerosene soot (Sheridan et al., 2005; Bergstrom et al., 2002; Moosmüller et al., 2009a). During the Reno aerosol optics study (Sheridan et al., 2005) the AAE for kerosene soot was measured to be in the range of 0.94 to 1.0. The Scattering Ångström Exponent (SAE) in our experiment is $\sim 1.611( \pm 0.005)$ as shown in Fig. 6b. For comparison, Gyawali et al. (2012) obtained a SAE of 1.88 for kerosene soot; we point out that the SAE is strongly dependent on particle size. The single scattering albedo as a function of wavelength is shown in Fig. $6 \mathrm{c}$ and is decreasing with increasing wavelength above $550 \mathrm{~nm}$ for both instruments. Measurements from the two instruments agree with each other within the statistical uncertainties of the data.

\subsection{Salt}

Common salt $(\mathrm{NaCl})$ aerosol is white $(\mathrm{SSA}=1)$ and is expected to show negligible absorption at visible wavelengths. Figure 7a shows the absorption coefficient of salt obtained from SC-PNS and PASS-3. The absorption coefficients from the two instruments are zero within their respective errors demonstrating, as expected, that scattering does not interfere with the absorption measurement, or in other words, the photoacoustic effect is insensitive to scattering. On the other hand, the values of scattering coefficients obtained from the two instruments show strong wavelength dependence (Fig. $7 b$ ). In view of the zero absorption, the single scattering albedo (Fig. 7c) had a constant value $\sim 1$, irrespective of wavelength.

\subsection{Nitrogen dioxide}

Nitrogen dioxide absorbs throughout the visible region and therefore can be used to evaluate the absorption measured by the SC-PNS. With this aim, we conducted an experiment by maintaining a continuous flow of 101.3( \pm 2$) \mathrm{ppm}$ (mole $\% \mathrm{NO}_{2}$ in air through the instrument. The difference between the scattering coefficient of particle free air and the $\mathrm{NO}_{2}$ mixture is negligible in the visible region, and therefore the measured extinction coefficient of the laser radiation should correspond to the absorption coefficient. The photoacoustic signal (expressed in units of inverse megameters as calibrated with kerosene soot) and the scattering coefficient were measured directly while the extinction coefficient was calculated from the laser powers measured with the extinction photodiode at the integrating sphere using Eq. (6).

$\beta_{\mathrm{ext}}=\left(\frac{-1}{L}\right) \ln \left(\frac{I}{I_{0}}\right)$

where, $I_{0}$ is the laser intensity measured while particle-free dry air was flowing through the instrument, $I$ is the laser intensity measured with the $101.3 \mathrm{ppm} \mathrm{NO} \mathrm{N}_{2}$ mixture flowing in the cell, and $L$ is the cell length. 

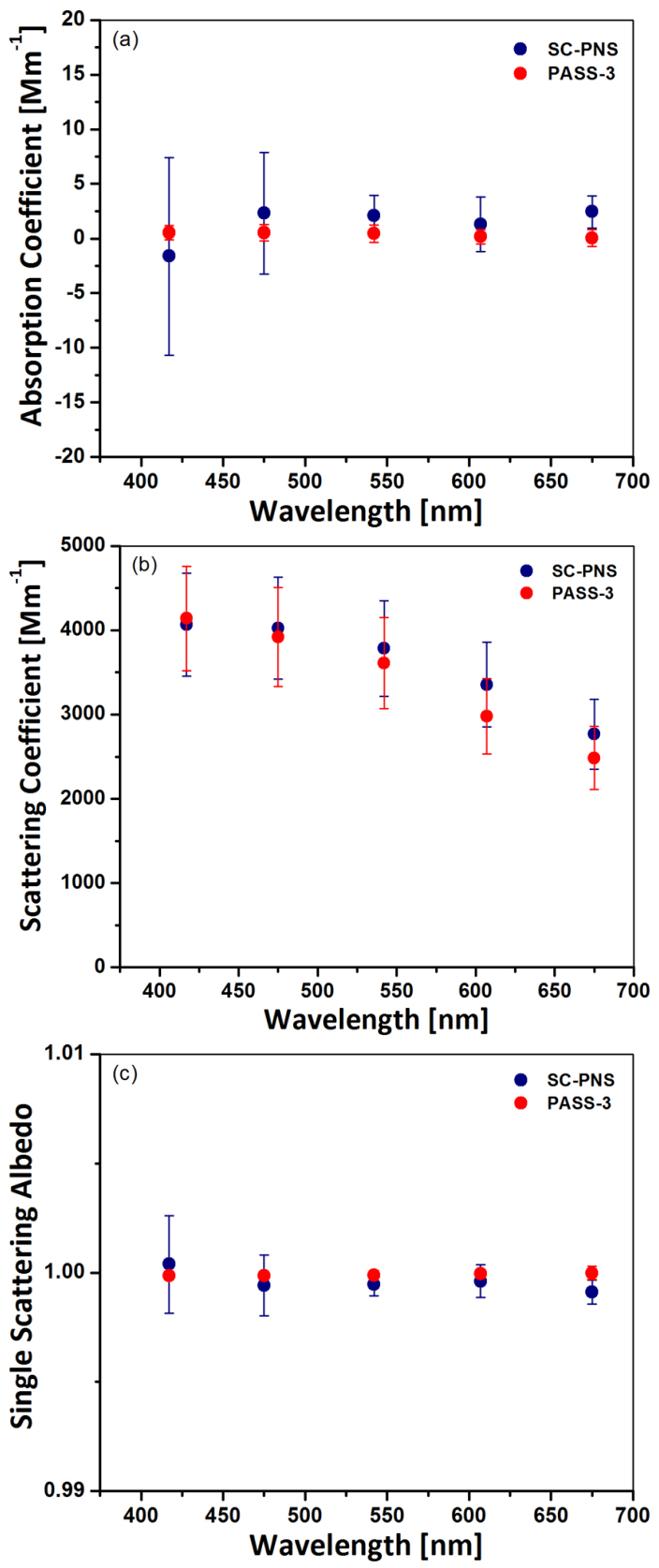

Fig. 7. (a) Absorption $\left(\beta_{\text {abs }}\right)$ and (b) scattering $\left(\beta_{\text {sca }}\right)$ coefficients of common salt $(\mathrm{NaCl})$ vs. wavelength $(\lambda)$ measured by PASS-3 and SC-PNS, error bars indicate square root of sum of squares of background error, standard deviation of mean (standard error) and calibration variability. (c) Single scattering albedo of salt, error bars indicate the error propagated from absorption and scattering.

The photoacoustic signal and the extinction coefficient obtained by our instrument at each wavelength band were compared to the absorption coefficients calculated from the $\mathrm{NO}_{2}$ absorption cross sections using the HITRAN database at 294 K (Orphal and Chance, 2003; Rothman et al., 2003). Figure $8 \mathrm{a}$ shows a plot of the photoacoustic signal and extinction coefficient measured by our instrument and the absorption coefficient from the HITRAN database as a function of wavelength and Fig. 8b shows a plot of the phtoacoustic signal and extinction coefficient measured as a function of the absorption coefficient from the HITRAN database for an $\mathrm{NO}_{2}$ concentration of $101.3 \mathrm{ppm}$. For a direct comparison, the absorption coefficient from the HITRAN database was weighted by the spectral radiance at each wavelength and integrated over the complete wavelength band of each filter to obtain the absorption coefficient for the corresponding filter. Absorption by $\mathrm{NO}_{2}$ decreases rapidly with increasing wavelengths while is accompanied by photodissociation at UV and blue wavelengths ( $\sim 289-422 \mathrm{~nm}$ ). The quantum yield of photodissociation for $\mathrm{NO}_{2}$ is approximately 1 up to $370 \mathrm{~nm}$ and then decreases rapidly reaching a value of 0.02 around $422 \mathrm{~nm}$ (Seinfeld and Pandis, 1998). Filter $1(417 \pm 60 \mathrm{~nm})$ has a bandwidth range from $386 \mathrm{~nm}$ to $456 \mathrm{~nm}$ which overlaps with the expected photodissociation range. Therefore, as expected, for filter 1 we measured a photoacoustic signal ( $\beta_{\text {abs }}$ PAS), which represents the response of the microphone, that is lower than the calculated $\mathrm{NO}_{2}$ absorption coefficient and the measured extinction coefficient (Tian et al., 2013). In Fig. 8a and b, the photoacoustic signal (correspondent to absorption only when photodissociation is negligible) is shown on a separate $y$ axis to differentiate it from the absorption by $\mathrm{NO}_{2}$ and to highlight the effect of photodissociation on the photoacoustic signal at the wavelength band corresponding to filter 1 . We corrected for the photodissociation effect by weighting the quantum yield $\varphi$ by the spectral radiance of filter $1\left(\varphi_{\text {net }}\right)$ and dividing the photacoustic signal by $\left(1-\varphi_{\text {net }}\right)$. The corrected $\beta_{\text {abs }}$ (represented in the graph by the hollow circle in Fig. $8 b$ ) is increased by a factor of $\sim 1.3$. No correction is needed for the other wavelength bands due to the negligible photodissociation quantum yield at these wavelengths. The extinction and the absorption coefficients (including the corrected value for filter 1$)$ lie on the $1: 1$ line ( $\beta_{\text {abs }}$ PAS and $\beta_{\text {ext }}$ PAS: $\beta_{\text {abs }}$ HITRAN) within the error limits. The uncertainty in the absorption coefficient calculated from the HITRAN database is calculated as the square root of the sum of squares of $2 \%$ uncertainty in $\mathrm{NO}_{2}$ concentration, as per gas specification, and $2 \%$ uncertainty in $\mathrm{NO}_{2}$ absorption cross section indicated in Orphal and Chance (2003). From our analysis and plot we omitted the absorption coefficient for the filter centered at $675 \mathrm{~nm}$ (filter 5), which was $\sim 1000 \mathrm{Mm}^{-1}$ because $\mathrm{NO}_{2}$ absorption cross sections beyond $663 \mathrm{~nm}$ are not available in the HITRAN database that we used.

The results of this experiment demonstrate the validity of the absorption calibration procedure discussed earlier, and indirectly also the scattering calibration, as the absorption calibration with kerosene soot is based on the difference between the extinction and the calibrated scattering signals, as previously discussed by Arnott et al. (2000). 

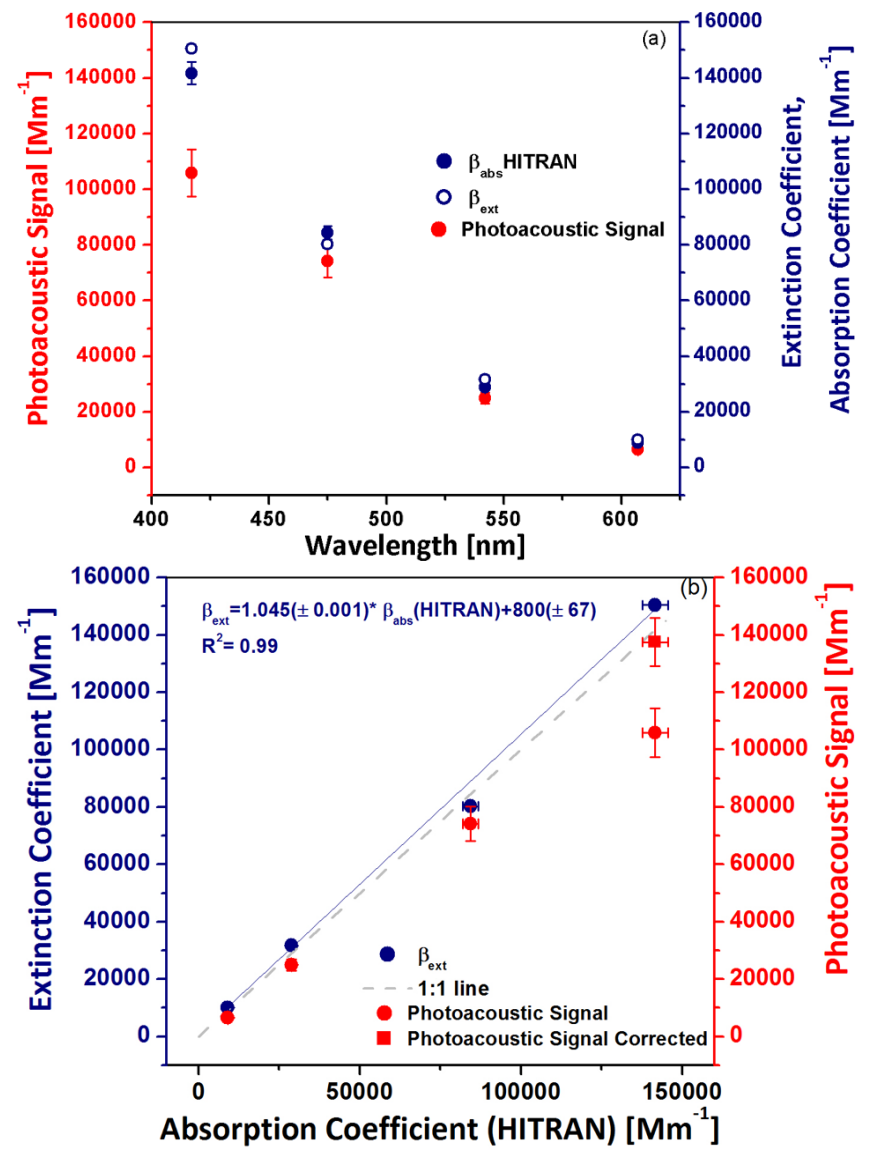

Fig. 8. (a) Extinction, photoacoustic signal measured by SC-PNS and absorption estimated from the HITRAN database vs. wavelength. (b) Extinction and absorption measured by SC-PNS vs. absorption estimated from the HITRAN database. The vertical error bars on the photoacoustic signal measured and corrected for photodissociation indicate the square root of the sum of squares of the standard deviation of the mean (standard error) and the calibration variability. Vertical error bars on $\beta_{\text {ext }}$ indicate the square root of the sum of squares of the standard deviation of the mean (standard error) and the propagated error from the laser power measurement. Horizontal errors on the absorption coefficient calculated from the HITRAN database include $2 \%$ uncertainty in $\mathrm{NO}_{2}$ absorption cross section and $2 \%$ uncertainty in the $\mathrm{NO}_{2}$ concentration.

\section{Instrumental noise and minimum detection limits versus integration time}

The instrumental noise and drifts were studied by operating the instrument with aerosol-free air (using indoor air filtered with a HEPA filter) for each wavelength band. The instrument stability and the minimum detection limit of the instrument were analyzed using Allan deviation plots. The instrument is considered to be stable for a length of time when the signal is free from drifts. Averaging the signal over this time reduces the noise and improves the signal to noise ratio, and hence the minimum detection limit of the instrument. For a
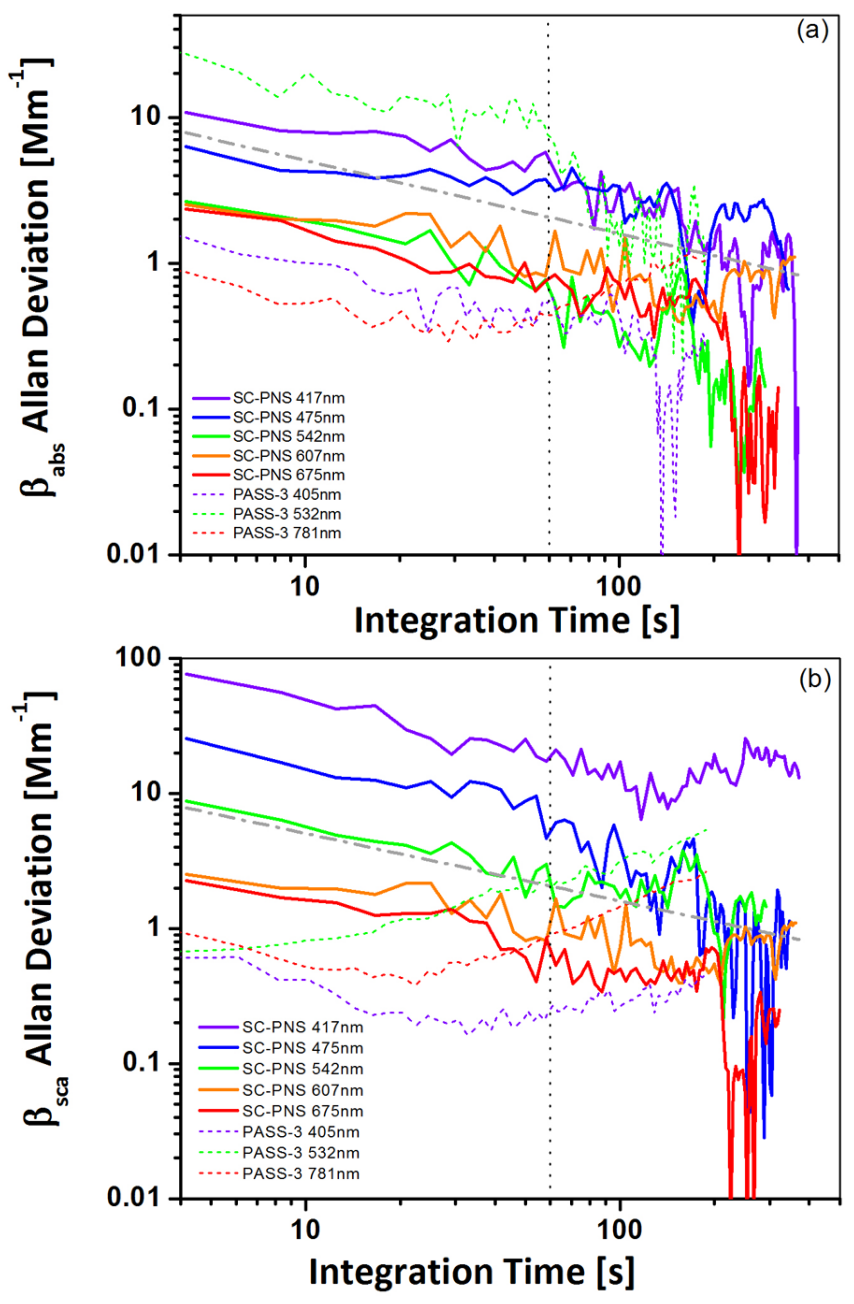

Fig. 9. Allan deviation vs. integration time plots for (a) absorption $\left(\beta_{\mathrm{abs}}\right)$ and (b) scattering $\left(\beta_{\mathrm{sca}}\right)$ coefficients at different wavelength bands for SC-PNS and at different wavelengths for PASS-3. Black dotted vertical and grey dashed lines indicate $60 \mathrm{~s}$ integration time and $1 /$ square root of integration time, respectively as guides to the eye.

signal which includes random noise and instrumental drift, the Allan deviation firstly decreases proportionally with the reciprocal of the square root of the averaging (integration) time and then increases as instrumental drift becomes significant (Werle et al., 1993; Skř́ńnský et al., 2009).

We used a Matlab code written by Fabian Czerwinski (Czerwinski, 2010) to calculate the Allan deviation for the absorption, scattering and extinction signals for the SC-PNS and the PASS-3 as shown in Fig. 9a and b, respectively. Table 3 lists the approximate values of minimum detectable absorption, scattering and extinction coefficients obtained at each wavelength band of the SC-PNS for an equal integration time of $60 \mathrm{~s}$. For comparison we also added the minimum detection limits at $60 \mathrm{~s}$ integration time similarly calculated for the PASS-3. 
Table 3. Minimum detectable absorption (MDA), scattering (MDS) and extinction (MDE) coefficients for $60 \mathrm{~s}$ integration time.

\begin{tabular}{|c|c|c|c|c|c|c|c|c|c|}
\hline $\begin{array}{r}\text { SC-PNS Center } \\
\text { wavelength [nm] }\end{array}$ & $\begin{array}{r}\text { MDA } \\
{\left[\mathrm{Mm}^{-1}\right]}\end{array}$ & $\begin{array}{r}\mathrm{MDS} \\
{\left[\mathrm{Mm}^{-1}\right]}\end{array}$ & $\begin{array}{r}\mathrm{MDE} \\
{\left[\mathrm{Mm}^{-1}\right]}\end{array}$ & $\begin{array}{r}\text { Laser power } \\
{[\mathrm{mW}]}\end{array}$ & $\begin{array}{r}\text { PASS-3 } \\
\text { Wavelength [nm] }\end{array}$ & $\begin{array}{r}\text { MDA } \\
{\left[\mathrm{Mm}^{-1}\right]}\end{array}$ & $\begin{array}{r}\text { MDS } \\
{\left[\mathrm{Mm}^{-1}\right]}\end{array}$ & $\begin{array}{r}\mathrm{MDE} \\
{\left[\mathrm{Mm}^{-1}\right]}\end{array}$ & $\begin{array}{r}\text { Laser power } \\
{[\mathrm{mW}]}\end{array}$ \\
\hline 417 & 4 & 21 & 1800 & 15.6 & 405 & 0.4 & 0.2 & 223 & 254 \\
\hline 475 & 3 & 6 & 2300 & 26.5 & - & - & - & & - \\
\hline 542 & 0.5 & 1.5 & 1500 & 45.6 & 532 & 8 & 1.7 & 16500 & 189 \\
\hline 607 & 2 & 1 & 1400 & 86.4 & - & - & - & & - \\
\hline 675 & 1 & 0.5 & 750 & 64.4 & - & - & - & & - \\
\hline- & - & - & & - & 781 & 0.3 & 0.8 & 84 & 501 \\
\hline
\end{tabular}

Minimum detectable absorption of $0.5,2$ and $1 \mathrm{Mm}^{-1}$ and minimum detectable scattering of less than $2 \mathrm{Mm}^{-1}$ can be achieved for 542, 607 and $675 \mathrm{~nm}$ wavelengths by integrating the signal for $\sim 60 \mathrm{~s}$. These values of minimum detectable absorption and scattering make the instrument capable of measuring ambient aerosols even in environments with medium aerosol concentrations.

\section{Conclusions}

We developed a new photoacoustic-nephelometer instrument using a supercontinuum laser as light source for the measurement of absorption and scattering coefficients of aerosol samples at multiple wavelengths (i.e., 417, 475, 542, 607, and $675 \mathrm{~nm}$ ). The instrument was tested with kerosene soot and common salt for the wavelength dependence of aerosol optical properties and the results obtained were compared to a simultaneously operating commercial 3-wavelength photoacoustic and nephelometer instrument (PASS-3). The values of absorption and scattering Ångström exponents obtained for soot from our instrument agree closely with values available in literature. Salt that has negligible absorption at visible wavelengths, showed negligible photoacoustic signal, demonstrating the lack of scattering interferences on the absorption measurements, in contrast to filter-based measurements. Scattering coefficients of salt aerosol as obtained by our instrument, showed wavelength dependence departing from a simple power law. The absorption and scattering coefficients obtained with the commercial instrument and interpolated on the supercontinuum wavelength bands agreed with the observations from the SC-PNS. The absorption coefficient as measured for the first four wavelength bands agree well with theoretical calculations when measuring a mixture of $\mathrm{NO}_{2}$ in air. As the instrument operates over broad wavelength bands, the knowledge of the spectral details of absorption by gaseous species is less critical than for single line laser-based photoacoustic systems.

The current version of the instrument measures scattering and absorption coefficients at each wavelength band, one at a time. This requires a stable size distribution and monotonic (or at least well-constrained) variation in the concentration of the sample particles, to measure accurate aerosol absorption and scattering spectra. Efforts toward the development of a field deployable instrument are currently under way by improving the current instrument to measure simultaneously at different wavelengths and to expand the measurement spectral region to the NIR to allow the characterization of aerosol optical properties over most of the solar spectrum. Due to the minimum detectable absorption and scattering coefficients, the instrument can find applications in laboratory as well as in field studies down to medium pollution environmental conditions. The instrument can provide valuable and unique information on the wavelength dependence of the optical properties of ambient and laboratory-generated aerosols.

Acknowledgements. This material is based upon work supported by the National Science Foundation under Grant No. AGS-1040046, by NASA EPSCoR under Cooperative Agreement No. NNX10AR89A, by NASA ROSES under Grant No. NNX11AB79G, by Michigan Tech start-up fund and by a Michigan Tech Research Excellence Fund-Research Seed Grant.

Edited by: A. Wiedensohler

\section{References}

Abu-Rahmah, A., Arnott, W. P., and Moosmüller, H.: Integrating nephelometer with a low truncation angle and an extended calibration scheme, Meas. Sci. Technol., 17, 1723-1732, 10.1088/0957-0233/17/7/010, 2006.

Ajtai, T., Filep, Á., Schnaiter, M., Linke, C., Vragel, M., Bozóki, Z., Szabó, G., and Leisner, T.: A novel multi- wavelength photoacoustic spectrometer for the measurement of the UV-visNIR spectral absorption coefficient of atmospheric aerosols, J. Aerosol Sci., 41, 1020-1029, 2010.

Alfano, R. and Shapiro, S.: Observation of self-phase modulation and small-scale filaments in crystals and glasses, Phys. Rev. Lett., 24, 592 - 594, doi:10.1103/PhysRevLett.24.592, 1970.

Andreae, M. O. and Gelencsér, A.: Black carbon or brown carbon? The nature of light-absorbing carbonaceous aerosols, Atmos. Chem. Phys., 6, 3131-3148, doi:10.5194/acp-6-3131-2006, 2006.

Arnold, I. J., Berger, C., Moosmuller, H., Sharma, N., and Mazzoleni, C.: The Iron Lung: A Device for the Continuous Delivery of Fine Particulate Matter, Rev. Sci. Instrum., under review, 2013. 
Arnott, W. P., Moosmüller, H., Rogers, C. F., Jin, T. F., and Bruch, R.: Photoacoustic spectrometer for measuring light absorption by aerosol: instrument description, Atmos. Environ., 33, 28452852, 1999.

Arnott, W. P., Moosmüller, H., and Walker, J. W.: Nitrogen dioxide and kerosene-flame soot calibration of photoacoustic instruments for measurement of light absorption by aerosols, Rev. Sci. Instrum., 71, 4545-4552, doi:10.1063/1.1322585, 2000.

Bergstrom, R. W., Russell, P. B., and Hignett, P.: Wavelength dependence of the absorption of black carbon particles: Predictions and results from the TARFOX experiment and implications for the aerosol single scattering albedo, J. Atmos. Sci., 59, 567-577, 2002.

Bergstrom, R. W., Pilewskie, P., Russell, P. B., Redemann, J., Bond, T. C., Quinn, P. K., and Sierau, B.: Spectral absorption properties of atmospheric aerosols, Atmos. Chem. Phys., 7, 5937-5943, doi:10.5194/acp-7-5937-2007, 2007.

Bond, T. C. and Bergstrom, R. W.: Light absorption by carbonaceous particles: An investigative review, Aerosol Sci. Technol., 40, 27-67, 2006.

Chamaillard, K., Jennings, S., Kleefeld, C., Ceburnis, D., and Yoon, Y.: Light backscattering and scattering by nonspherical sea-salt aerosols, J. Quant. Spetrosc. Radiat. Transfer, 79, 577-597, 2003.

Chen, Y. and Bond, T. C.: Light absorption by organic carbon from wood combustion, Atmos. Chem. Phys., 10, 1773-1787, doi:10.5194/acp-10-1773-2010, 2010.

Chýlek, P. and Wong, J.: Effect of absorbing aerosols on global radiation budget, Geophys. Res Lett., 22, 929-931, 1995.

Chýlek, P., Videen, G., Ngo, D., Pinnick, R. G., and Klett, J. D.: Effect of black carbon on the optical properties and climate forcing of sulfate aerosols, J. Geophys. Res., 100, 16325-16332, doi:10.1029/95jd01465, 1995.

Cross, E. S., Onasch, T. B., Ahern, A., Wrobel, W., Slowik, J. G., Olfert, J., Lack, D. A., Massoli, P., Cappa, C. D., and Schwarz, J. P.: Soot particle studies-instrument inter-comparison-project overview, Aerosol. Sci. Tech., 44, 592-611, 2010.

Czerwinski, F.: allan v3.0 MAtlabCentral, available at: http://www. mathworks.com/matlabcentral/fileexchange/26659-allan-v3-0, (last access: 17 December 2012), 2010.

Dudley, J. M., Genty, G., and Coen, S.: Supercontinuum generation in photonic crystal fiber, Rev. Mod Phys., 78, 1135, doi:10.1103/RevModPhys.78.1135, 2006.

Flowers, B. A., Dubey, M. K., Mazzoleni, C., Stone, E. A., Schauer, J. J., Kim, S.-W., and Yoon, S. C.: Optical-chemicalmicrophysical relationships and closure studies for mixed carbonaceous aerosols observed at Jeju Island; 3-laser photoacoustic spectrometer, particle sizing, and filter analysis, Atmos. Chem. Phys., 10, 10387-10398, doi:10.5194/acp-10-10387-2010, 2010.

Gyawali, M., Arnott, W. P., Zaveri, R. A., Song, C., Moosmüller, H., Liu, L., Mishchenko, M. I., Chen, L.-W. A., Green, M. C., Watson, J. G., and Chow, J. C.: Photoacoustic optical properties at UV, VIS, and near IR wavelengths for laboratory generated and winter time ambient urban aerosols, Atmos. Chem. Phys., 12, 2587-2601, doi:10.5194/acp-12-2587-2012, 2012.

Gyawali, M., Arnott, W. P., Zaveri, R. A., Song, C., Pekour, M., Flowers, B., Dubey, M. K., Setyan, A., Zhang, Q., Harworth, J. W., Radney, J. G., Atkinson, D. B., China, S., Mazzoleni, C., Gorkowski, K., Subramanian, R., Jobson, B. T., and Moosmüller, H.: Evolution of multispectral aerosol optical proper- ties in a biogenically-influenced urban environment during the CARES campaign, Atmos. Chem. Phys. Discuss., 13, 71137150, doi:10.5194/acpd-13-7113-2013, 2013.

Haisch, C., Menzenbach, P., Bladt, H., and Niessner, R. R.: A wide spectral range photoacoustic aerosol absorption spectrometer, Anal. Chem., 84, 8941-8945, doi:10.1021/ac302194u, 2012.

Heintzenberg, J. and Charlson, R. J.: Design and applications of the integrating nephelometer: A review, J. Atmos. Ocean. Tech., 13, 987-1000, 1996.

Horvath, H.: Atmospheric light absorption - a review, Atmos. Environ A-Gen., 27, 293-317, 1993.

Irshad, R., Grainger, R. G., Peters, D. M., McPheat, R. A., Smith, K. M., and Thomas, G.: Laboratory measurements of the optical properties of sea salt aerosol, Atmos. Chem. Phys. Discuss., 8, 71-94, doi:10.5194/acpd-8-71-2008, 2008.

Knight, J. C.: Photonic crystal fibres, Nature, 424, 847-851, 2003.

Lack, D. A., Lovejoy, E. R., Baynard, T., Pettersson, A., and Ravishankara, A. R.: Aerosol absorption measurement using photoacoustic spectroscopy: Sensitivity, calibration, and uncertainty developments, Aerosol Sci. Tech., 40, 697-708, doi:10.1080/02786820600803917, 2006.

Lack, D. A., Cappa, C. D., Covert, D. S., Baynard, T., Massoli, P., Sierau, B., Bates, T. S., Quinn, P. K., Lovejoy, E. R., and Ravishankara, A.: Bias in filter-based aerosol light absorption measurements due to organic aerosol loading: Evidence from ambient measurements, Aerosol Sci. Tech., 42, 1033-1041, 2008.

Lack, D. A., Langridge, J. M., Bahreini, R., Cappa, C. D., Middlebrook, A. M., and Schwarz, J. P.: Brown carbon and internal mixing in biomass burning particles, P. Natl. Acad. Sci. USA, 109, 14802-14807, 2012.

Lewis, K., Arnott, W. P., Moosmüller, H., and Wold, C. E.: Strong spectral variation of biomass smoke light absorption and single scattering albedo observed with a novel dual-wavelength photoacoustic instrument, J. Geophys. Res.-Atmos., 113, D16203, doi:10.1029/2007jd009699, 2008.

Marcos, A.: Deriving the basic cell-reciprocal integrating nephelometer equation and its use for calibration purposes: a comprehensive approach, Meas. Sci. Technol., 10, R1-R15, 1999.

Moosmüller, H. and Arnott, W. P.: Particle Optics in the Rayleigh Regime, JAPCA J. Air Waste MA., 59, 1028-1031, doi:10.3155/1047-3289.59.9.1028, 2009a.

Moosmüller, H., Chakrabarty, R. K., and Arnott, W. P.: Aerosol light absorption and its measurement: A review, J. Quant. Spectrosc. Radiat. Transfer, 110, 844-878, doi:10.1016/j.jqsrt.2009.02.035, 2009 b.

Moosmüller, H., Chakrabarty, R. K., Ehlers, K. M., and Arnott, W. P.: Absorption Ångström coefficient, brown carbon, and aerosols: basic concepts, bulk matter, and spherical particles, Atmos. Chem. Phys. Discuss., 10, 24735-24761, doi:10.5194/acpd-1024735-2010, 2010.

Moosmüller, H., Engelbrecht, J. P., Skiba, M., Frey, G., Chakrabarty, R. K., and Arnott, W. P.: Single scattering albedo of fine mineral dust aerosols controlled by iron concentration, J. Geophys. Res., 117, D11210, doi:10.1029/2011jd016909, 2012.

Orphal, J. and Chance, K.: Ultraviolet and visible absorption crosssections for HITRAN, J. Quant. Spectrosc. Radiat. Transfer, 82, 491-504, 2003.

Ramanathan, V., Chung, C., Kim, D., Bettge, T., Buja, L., Kiehl, J., Washington, W., Fu, Q., Sikka, D., and Wild, M.: Atmospheric 
brown clouds: Impacts on South Asian climate and hydrological cycle, P. Natl. Acad. Sci. USA, 102, 5326-5333, 2005.

Ranka, J. K., Windeler, R. S., and Stentz, A. J.: Visible continuum generation in air-silica microstructure optical fibers with anomalous dispersion at $800 \mathrm{~nm}$, Opt. Lett., 25, 25-27, 2000.

Rosencwaig, A.: Photoacoustics and Photoacoustic Spectroscopy, Wiley, New York NY, 1980.

Rothman, L., Barbe, A., Chris Benner, D., Brown, L., Camy-Peyret, C., Carleer, M., Chance, K., Clerbaux, C., Dana, V., and Devi, V. M.: The HITRAN molecular spectroscopic database: edition of 2000 including updates through 2001, J. Quant. Spectrosc. Radiat. Transfer, 82, 5-44, 2003.

Roy, A., Leproux, P., Roy, P., Auguste, J.-L., and Couderc, V.: Supercontinuum generation in a nonlinear Yb-doped, double-clad, microstructured fiber, J. Opt. Soc. Am. B, 24, 788-791, 2007.

Russell, P.: Photonic Crystal Fibers, Science, 299, 358-362, 2003.

Schnaiter, M., Gimmler, M., Llamas, I., Linke, C., Jäger, C., and Mutschke, H.: Strong spectral dependence of light absorption by organic carbon particles formed by propane combustion, Atmos. Chem. Phys., 6, 2981-2990, doi:10.5194/acp-6-2981-2006, 2006.

Scofield, J. H.: Frequency-domain description of a lock-in amplifier, Am. J. Phys., 62, 129-132, 1994.

Scott, R. P., Langrock, C., and Kolner, B. H.: High-dynamic-range laser amplitude and phase noise measurement techniques, IEEE J. Sel. Top. Quant., 7, 641-655, doi:10.1109/2944.974236, 2001.

Seinfeld, J. H. and Pandis, S. N.: Atmospheric Chemistry and Physics, Wiley-Interscience Publication, New York, USA, 125162,1998

Sheridan, P. J., Arnott, W. P., Ogren, J. A., Andrews, E., Atkinson, D. B., Covert, D. S., Moosmüller, H., Petzold, A., Schmid, B., Strawa, A. W., Varma, R., and Virkkula, A.: The Reno Aerosol Optics Study: An evaluation of aerosol absorption measurement methods, Aerosol Sci. Tech., 39, 1-16, doi:10.1080/027868290901891, 2005.
Skřínský, J., Janečková, R., Grigorová, E., Střižík, M., Kubát, P., Herecová, L., Nevrlý, V., Zelinger, Z., and Civiš, S.: Allan variance for optimal signal averaging - monitoring by diode - laser and $\mathrm{CO}_{2}$ laser photo-acoustic spectroscopy, J. Mol. Spectrosc., 256, 99-101, 2009.

Solomon, S., Qin, D., Manning, M., Chen, Z., Marquis, M., Averyt, K. B., Tignor, M., and Miller, H. L. (Eds.): IPCC, 2007: Climate Change 2007: The Physical Science Basis. Contribution of Working Group I to the Fourth Assessment Report of the Intergovernmental Panel on Climate Change, Cambridge University Press, Cambridge, United Kingdom and New York, NY, USA, 996 pp., 2007.

Sun, H., Biedermann, L., and Bond, T. C.: Color of brown carbon: A model for ultraviolet and visible light absorption by organic carbon aerosol, Geophys. Res. Lett., 34, L17813, doi:10.1029/2007GL029797, 2007.

Tam, A. C.: Applications of photoacoustic sensing techniques, Rev. Mod. Phys., 58, 381-431, 1986.

Tang, I. N., Wong, W. T., and Munkelwitz, H. R.: The relative importance of atmospheric sulfates and nitrates in visibility reduction, Atmos. Environ. (1967), 15, 2463-2471, doi:10.1016/00046981(81)90062-7, 1981.

Tian, G., Moosmüller, H., and Arnott, W. P.: Influence of Photolysis on Multispectral Photoacoustic Measurement of Nitrogen Dioxide Concentration, JAPCA J. Air Waste Ma., 63, 1091-1097, doi:10.1080/10962247.2013.790323, 2013.

Werle, P., Mücke, R., and Slemr, F.: The limits of signal averaging in atmospheric trace-gas monitoring by tunable diode-laser absorption spectroscopy (TDLAS), Appl. Phys. B-Lasers O., 57, 131-139, 1993. 